Down- regul at $i$ on of

Cal ci um/Cal nodul i $n$ - dependent prot ei $n$ ki nase ki nase 2 by androgen depr i vat i on i nduces cast rat i on- resi st ant prost at e cancer

\begin{tabular}{|c|c|}
\hline 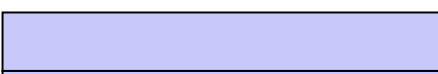 & 島 崇 \\
\hline 著者別表示 & Shi ma Takashi \\
\hline $\begin{array}{l}\text { j our nal or } \\
\text { publ i cat } i \text { on } \mathrm{title}\end{array}$ & 博士論文本文Ful I \\
\hline 学位授与番号 & 13301甲第3919号 \\
\hline 学位名 & 博士 (医学) \\
\hline 学位授与年月日 & $2013-06-30$ \\
\hline URL & ht t p: //hdl . handl e. net /2297/39448 \\
\hline
\end{tabular}




\title{
Down-Regulation of Calcium/Calmodulin-Dependent Protein Kinase Kinase 2 by Androgen Deprivation Induces Castration-Resistant Prostate Cancer
}

\author{
Takashi Shima, ${ }^{1}$ Atsushi Mizokami, ${ }^{1 *}$ Toru Miyagi, ${ }^{1}$ Keiichi Kawai, ${ }^{2}$ Kouji Izumi, ${ }^{1}$ \\ Misako Kumaki, ${ }^{1}$ Mitsuo Ofude, ${ }^{1}$ Jian Zhang, ${ }^{3}$ Evan T. Keller, ${ }^{4}$ and Mikio Namiki ${ }^{1}$ \\ 'Department of Integrative CancerTherapy and Urology, Kanazawa University Graduate School of Medical Sciences, \\ Ishikawa, Japan \\ ${ }^{2}$ Division of Health Sciences, Graduate School of Medical Science, Kanazawa University, Ishikawa, Japan \\ ${ }^{3}$ Guangxi Medical University, Pharmacology and Biomedical Sciences, Guangxi, China \\ ${ }^{4}$ Departments of Urology and Pathology, University of Michigan, Ann Arbor, Minnesota
}

\begin{abstract}
BACKGROUND. Conversion into androgen-hypersensitive state and adaptation to the low concentration of androgen during ADT cause relapse of prostate cancer (PCa). It is important to identify differentially expressed genes between $\mathrm{PCa}$ and normal prostate tissues and to reveal the function of these genes that are involved in progression of PCa.

METHODS. We performed cDNA microarray analysis to identify differentially expressed genes, calcium/calmodulin-dependent protein kinase kinase 2 (CAMKK2). Immunohistochemical analysis was conducted to investigate the relationship between the CAMKK2 expression level and prognosis. The function of CAMKK2 was assessed by generating CAMKK2 overexpressed LNCaP cells and by knockdown of CAMKK2.

RESULTS. We identified CAMKK2 overexpressed six times in PCa more than normal prostate by cDNA microarray analysis. Immunohistochemical analysis of CAMKK2 protein showed that CAMKK2 protein was expressed more in PCa than normal tissue. However, the expression in the high-grade PCa diminished. Moreover, the narrowness of CAMKK2positive area before ADT was a poor prognostic factor. Androgen-deprivation treatment from the medium in which $\mathrm{LNCaP}$ cells were cultured in the presence of $10 \mathrm{nM}$ DHT repressed CAMKK2 expression. CAMKK2 overexpressed LNCaP cells (LNCaP/GFPCAMKK2) attenuated androgen-sensitivity. Tumorigenesis of LNCaP/GFP-CAMKK2 cells in male SCID mice was decreased compared with control cells irrespective of castration. Finally, knockdown of CAMKK2 mRNA in LNCaP cells induced androgen-hypersensitivity and stimulated LNCaP cell proliferation.

CONCLUSIONS. Induction of androgen-hypersensitivity after ADT may be involved in down-regulation of CAMKK2. This result may provide new therapeutic approach to keep androgen-sensitivity of PCa after ADT. Prostate 72: 1789-1801, 2012. (C) 2012 Wiley Periodicals, Inc.
\end{abstract}

KEY WORDS: $\quad$ CAMKK2; prostate cancer; androgen-hypersensitivity; AMPK

Additional supporting information may be found in the online version of this article.

Grant sponsor: Ministry of Education, Culture, Sport, Science, and Technology of Japan; Grant number: 21592037.

The authors declare no conflict of interest.

*Correspondence to: Atsushi Mizokami, Department of Integrative Cancer Therapy and Urology, Kanazawa University Graduate
School of Medical Sciences, 13-1 Takaramachi, Kanazawa, Ishikawa 920-8640, Japan. E-mail: mizokami@ med.kanazawa-u.ac.jp Received 29 January 2012; Accepted 3 April 2012 DOI 10.1002 / pros. 22533

Published online 1 May 2012 in Wiley Online Library (wileyonlinelibrary.com). 


\section{INTRODUCTION}

Prostate cancer (PCa) is the most common malignancy and the second leading cause of cancer-related death of men in the United States [1]. Since advanced $\mathrm{PCa}$ is initially dependent upon androgens, androgen-deprivation therapy (ADT) is the first choice for advanced PCa. Improvement of symptom or decrease in prostate-specific antigen (PSA) is observed in more than $90 \%$ of PCa patients by ADT. Unfortunately, after an initial response to ADT, PCa eventually loses responsiveness to the androgen blockade and progresses into castration-resistant prostate cancer (CRPC).

Although multiple molecular mechanisms that could explain the development to CRPC have been proposed [2], androgen receptor (AR) is still a key mediator in the progression of PCa [3]. Especially, an androgen-hypersensitive situation of PCa plays an important role in an adaptation to castrate levels of androgen that is secreted from adrenal gland. Furthermore, intratumoral androgen synthesis in $\mathrm{PCa}$ or bone metastasis region also supplies androgen enough for androgenhypersensitive $\mathrm{PCa}$ cells to survive and proliferate [4,5]. Moreover, not only cancer cells but also cancerassociated fibroblasts coordinately synthesize dihydrotestosterone (DHT) from adrenal androgen DHEA, activate AR, and enhanced the cell proliferation after ADT [5].

As for androgen-hypersensitivity, CRPC is induced by several pathways: (A) promiscuous AR mutations. AR with T877A and H874Y mutation responds to various ligands, such as DHEA, estradiol, and progesterone [6,7]. (B) AR overexpression by AR gene amplification [8], increase of AR promoter activity, or AR mutation that increase AR stability [9]. (C) Increase of AR coactivators. Expression AR coactivator ARA55 and TIFII was increased in some of CRPC patients $[10,11]$. (D) Outlaw pathways through transactivation of kinases, or crosstalk with cytokines or growth factor receptors [2]. AR coactivator p300 and interleukin-6 coordinately activate $\mathrm{AR}$ and induce PSA [12].

To identify biomarkers for PCa and key proteins that induce carcinogenesis and progression during ADT, gene expression profiling between normal prostate and PCa was investigated using cDNA microarray technique [13-16]. As a result, many molecules have been identified as PCa markers, such as AMACR ( $\alpha$-methylacyl coenzyme A racemase), as prognostic biomarkers, such as MUC1 and AZGP1 [17], and as the proteins that induce progression such as the polycomb gene EZH2 [18]. Holzbeierlein et al. [13] demonstrated that overexpression of AR mRNA was also observed in CRPC. Overexpression of the AR could contribute to androgen-hypersensitivity in the low concentration of androgen. Moreover, they also identified some of the genes that were differentially expressed in resistant tumors and that could contribute to the process of reactivation.

In the present study, we also identified many genes that were differentially expressed between normal prostate and PCa tissue, and investigated the functions of them. Then we focused on one of overexpressed genes in $\mathrm{PCa}$, calcium/calmodulindependent protein kinase kinase 2 (CAMKK2). Recently, Frigo et al. [19] and Massie et al. [19] reported that CAMKK2 induced by androgen in PCa cells stimulated migration, invasion, and cell growth. However, we report that the size of CAMKK2positive area was inversely correlated with prognosis and that down-regulation of CAMKK2 expression by ADT increases the AR function and induces androgen-hypersensitivity.

\section{MATERIALS AND METHODS}

\section{cDNA Microarray Analysis}

In order to identify the differentially expressed genes between normal prostate and PCa tissue, we compared expression profile between each of three normal prostate biopsy samples and each of three PCa samples using cDNA microarray analysis. The characteristics of the patients were described in Table I. cDNA microarray analysis was performed in DNA Chip Research Inc. (Kanagawa, Japan) after sending biopsy samples from the patients and analyzed by Whole Human Genome Microarray $4 \times 44 \mathrm{~K}$ (Agilent Technologies; GEO accession number: GSE30994). Needle biopsies were performed after we obtained informed consent from patients with the document approved from the Graduate School of Medical Science, Kanazawa University.

\section{Cell Lines and Generation of StableTransformant}

LNCaP and VCaP cells (ATCC, Manassas, VA) were cultured in DMEM supplemented with $1 \%$ penicillin/streptomycin (Invitrogen, Carlsbad, CA) and $5 \%$ and $10 \%$ fetal bovine serum (Sigma-Aldrich, St. Louis, MO), respectively. To generate CAMKK2overexpressed LNCaP cells, LNCaP cells were transfected with $0.5 \mu \mathrm{g}$ pCMV6-AC-GFP or pCMV6AC-GFP-CAMKK2 from OriGene Technologies (Rockville, MD) using Lipofectamine reagent (Invitrogen). Eight hours after transfection, the cells were cultured at 1,200 $\mu \mathrm{g} / \mathrm{ml}$ G418 (Sigma-Aldrich) and selected as stable GFP and GFP-CAMKK2 overexpressing cells. 
TABLE I. Characteristics of the Patients

\begin{tabular}{|c|c|c|c|c|}
\hline Patients & Age & $\begin{array}{c}\text { PSA } \\
(\mathrm{ng} / \mathrm{ml})\end{array}$ & Gleason score & Stage \\
\hline P01 & 59 & 3.6 & ВРН (33 g) & \\
\hline P02 & 74 & 8.97 & $\mathrm{BPH}(67 \mathrm{~g})$ & \\
\hline P03 & 70 & 5.09 & ВPH (50 g) & \\
\hline P11 & 77 & 55 & $4+4=8$ & T3a, N0, M0 \\
\hline P12 & 72 & 227.8 & $4+4=8$ & $\mathrm{~T} 4, \mathrm{~N} 1, \mathrm{M} 0$ \\
\hline P13 & 82 & 96.7 & $4+3=7$ & T3a, N0, M0 \\
\hline
\end{tabular}

$\mathrm{BPH}$, benign prostate hypertrophy.

\section{Cell Proliferation Assay}

Twenty-four hours after cells were plated at a density of $5 \times 10^{4}$ cells onto 12-well plates with MDEM$5 \%$ charcoal-stripped fetal calf serum (CCS; Thermo Scientific HyClone, UK), cells were treated with or without DHT in DMEM-5\% CCS and the medium was changed every 2 days. In each experiment, cells were harvested and the numbers of the cells were counted in triplicate using a hemocytometer. The data represent the means $\pm \mathrm{SD}$ of three replicates.

\section{RNA Interference Analysis}

The specific Stealth CAMKK2 and AR small interfering RNAs (siRNAs) were synthesized by Invitrogen. CAMKK2 target siRNA-01 and -02 sequence were 5'-UUCGAACACCAUGUACAGAUGGUCC-3', 5'-CAAUGAAGGACUCCAUGCCCAGG-UG-3', respectively. Non-target (NT) siRNA were purchased from Invitrogen. For CAMKK2 knockdown, LNCaP cells were plated into 12 -well plates at $5 \times 10^{4}$ cells / well. After cultured for $24 \mathrm{hr}$, cells were transfected with each density of $20 \mathrm{nM}$ CAMKK2 siRNA or NT siRNA using Lipofectamine RNAiMAX Reagent (Invitrogen) for $24 \mathrm{hr}$. Total RNA or total proteins were exacted after siRNA transfection. For cell proliferation, after transfection of cells with NT siRNA or CAMKK2 siRNA-01 for $12 \mathrm{hr}$, cells were treated with $0,0.1,1.0$, and $10 \mathrm{nM}$ DHT, and the numbers of the cells were counted 4 days after transfection. Medium was changed every 2 days and DHT was also added to the medium.

\section{RT-PCR}

Total RNA extraction from cell cultures and RTPCR was performed followed as described previously [5]. The sense and anti-sense primers used RT-PCR of CAMKK2 are 5'-CTGGACATGAACGGACGCTGCA-

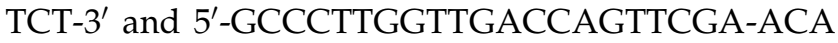
$\mathrm{C}-3^{\prime}$, respectively. The annealing temperature of RT-
PCR of CAMKK2 was $65^{\circ} \mathrm{C}$ and PCR cycle number was 30 cycles. The amplified PCR products were visualized using electrophoresis on a 1.5\% agarose gel. For quantification of mRNA expression, the gene expression in each sample was normalized by GAPDH gene expression.

\section{Luciferase Assay}

To evaluate AR transcriptional activity, $24 \mathrm{hr}$ after plating $5 \times 10^{4}$ cells on 12-well plates in DMEM-5\% CCS, LNCaP and its sublimes were transfected using Lipofectamine transfection reaction (Invitrogen) using $0.5 \mu \mathrm{g}$ of luciferase reporter plasmid, pGLPSAp-5.8, driven by a $5.8 \mathrm{~kb}$ PSA promoter including 3 androgen-response elements (ARE) [21]. Twelve hours after transfection, cells were treated by the addition of indicated concentration of DHT for $24 \mathrm{hr}$. After treated cells were harvested, cells were lysed in luciferaselysis buffer (Promega, WI). As for knockdown CAMKK2 expression in LNCaP cells, $5 \times 10^{4} \mathrm{LNCaP}$ cells were transfected with $20 \mathrm{nM}$ NT siRNA or CAMKK2 siRNA (Invitrogen) using RNAiMAX (Invitrogen) for $12 \mathrm{hr}$ and then LNCaP cells were further transfected with pGL3PSAp-5.8 for $12 \mathrm{hr}$. After changing medium, transfected LNCaP cells were cultured for $24 \mathrm{hr}$ and harvested.

\section{Western Blot Analysis}

After finishing various treatments, total protein was extracted from cells as described previously [22]. Protein was quantified according to the method of Bradford, and equal amounts of protein were electrophoresed on a $10 \%$ or $12.5 \%$ Ready Gel J (Bio-Rad, Hercules, CA). Membranes were incubated with mouse monoclonal antibody against CAMKK2 (SigmaAldrich), GAPDH (Novus Biologicals, Littleton, CO), AR (NH27) [23]. Horseradish peroxidase-conjugated secondary antibody against anti-mouse monoclonal or anti-rabbit monoclonal antibody was used and protein bands were visualized and quantitated with chemiluminescent reagent (SuperSignal West Pico Chemiluminescent Substrate; Pierce, Rockford, IL) and ChemiDoc XRS (Bio-Rad)

\section{Animal Study}

Severe combined immunodeficient (SCID) mice were castrated 1 week before implantation of LNCaP/GFP and LNCaP/GFP-CAMKK2 cells. The cells were combined with $50 \%$ Matrigel (Collaborative Biomedical Products, Bedford, MA) and $2 \times 10^{6}$ cells were prepared for injection into the dorsal subcutis of 6-week-old male SCID mice castrated 1 week ago and 6-week-old male SCID mice simultaneously. The 
dorsal tumor volume and body weights were monitored. Tumor growth was assessed by electronic caliper measurement of tumor diameter in two dimensions, and the tumor volume $(\mathrm{V})$ was calculated from the length (L) and width (W) according to the formula $\mathrm{V}=\mathrm{LW}^{2} / 2$. Serum from mice was taken for enzyme immunoassay of prostate-specific antigen (PSA) just before sacrifice and was frozen until measurement. To measure the concentration of PSA in serum of SCID mice, we asked SRL (Special Reference Laboratories, Inc. Japan). This animal protocol was approved by the Institutional Animal Care and Use Committee of the Graduate School of Medical Science, Kanazawa University.

\section{Immunohistochemistry of CAMKK2}

TM0016 tissue microarrays (TMAs) comprised of 80 cores containing normal tissue, matched for Gleason score at Sutgery were purchased from Provitro (Berlin, Germany) and PR952 TMAs comprised of 95 cores were purchased from Biomax (Rockville, MD). The procedure for immunohistochemical staining (IHC) was performed using a Dako ChemMate ENVISION Kit/HRP(DAB)-universal kit (K5007) according to the manufacturer's protocol (Dako, Carpinteria, CA). Tissue specimens were stained with mouse monoclonal antibodies against CAMKK2 (a dilution of 1:200; Sigma-Aldrich). Japanese patient's prostate tissues were obtained from needle biopsy of prostate on diagnosis in Kanazawa University Hospital. We picked up advanced PCa patients with bone metastasis. We obtained informed consent of patients for research and were admitted our research in the Institutional Review Board of the Graduate School of Medical Science, Kanazawa University. The procedure for IHC staining was the same of tissue microarray except dilution of the primary antibody at 1:400.

\section{Immunofluorescence Staining}

Methods of immunofluorescence staining was followed by previous study [24]. Briefly, staining for CAMKK2 protein was performed by overnight incubation using commercial kits in accordance with the manufacturer's instructions (Phallotoxins and Zenon $^{\mathrm{TM}}$ Tricolor Mouse and Rabbit IgG Labeling Kit; Molecular Probes, Eugene, OR). We compared the rate of a regional area with positive CAMKK2 expression with PSA-progression-free survival (PFS).

\section{Statistical Analysis}

Statistical significance was determined by using the Prism 4.0 software. The chi-square test was utilized to assess the significance between different proportions. Analysis of continuous variables between different groups was assessed by one-way analysis of variance followed by Fisher's protected least significant difference test. ${ }^{*},{ }^{* *}$, and ${ }^{* * *}$ represent significant difference $P<0.05, P<0.01$, and $P<0.001$, respectively. Kruskal-Wallis test was used to determine the statistical significance of differences in IHC staining of tissue microarray. Logistic regression analysis was used to determine correlation of CAMKK2 staining area and PFS.

\section{RESULTS}

\section{Identification of Differentially Expressed CAMKK2 Between Prostate Cancer and Normal Prostate}

To identify differentially expressed genes between normal prostate and PCa tissue, approximately 40,000 genes were screened by cDNA microarray analysis using mRNA from six different prostate biopsy samples from as described in Materials and Methods section (Table I). Seventy-nine $(0.2 \%)$ of screened genes were up-regulated $(\geq 2.5$-fold) and $124(0.31 \%)$ of genes were down-regulated in each of three PCa samples ( $\leq 0.25$-fold) compared with each of three normal prostate samples. Then we focused on CAMKK2 (calcium/calmodulin-dependent protein kinase kinase 2) which was a relatively highly expressed and $>6$-fold up-regulated in three $\mathrm{PCa}$ tissues compared with three normal prostate tissues.

First, we investigated if the CAMKK2 expression pattern on cDNA microarray is correlated with clinical PCa samples. As shown in Figure 1A-C, we classified intensity of the CAMKK2 staining of cytoplasm in three phases. Immunohistochemistry (IHC) of CAMKK2 using tissue microarray revealed that $87.8 \%$ $(115 / 131)$ cases of primary PCa tissue and $85.7 \%$ (6/ 7) cases of bone metastasis showed positive staining in cytoplasm, whereas only $4.2 \%(1 / 24)$ of normal prostate showed positive staining $(P<0.01$; Fig. 1D). Interestingly, the ratio of CAMKK2-negative staining rather diminished in the PCa tissue with the high Gleason score 8, 9, and 10 significantly compared with low Gleason score $(P=0.014)$. Therefore, we also investigated the correlation between CAMKK2 expression and prognosis (progression-free survival, PFS) of Japanese advanced PCa patients treated with first-line androgen-deprivation therapy (ADT). All patients had a diagnosis of the advanced PCa with bone metastases. Since PCa is multifocal disease and the transected tissue area can vary significantly in composition of cell type, we evaluated biopsy samples at the area of CAMKK2-positive cells. As shown in Figure 1E, regardless of an intensity of the expression of CAMKK2, the patients with area that 

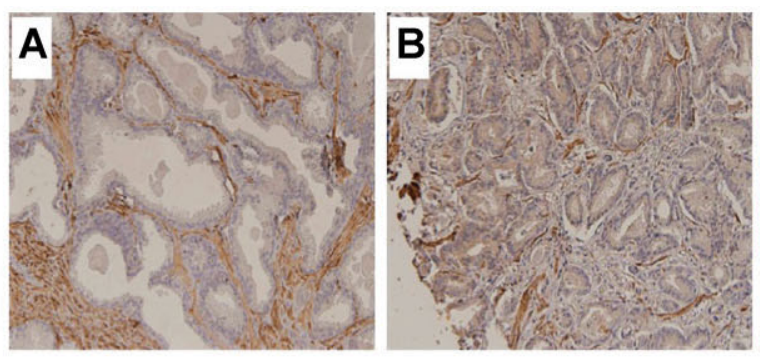

D

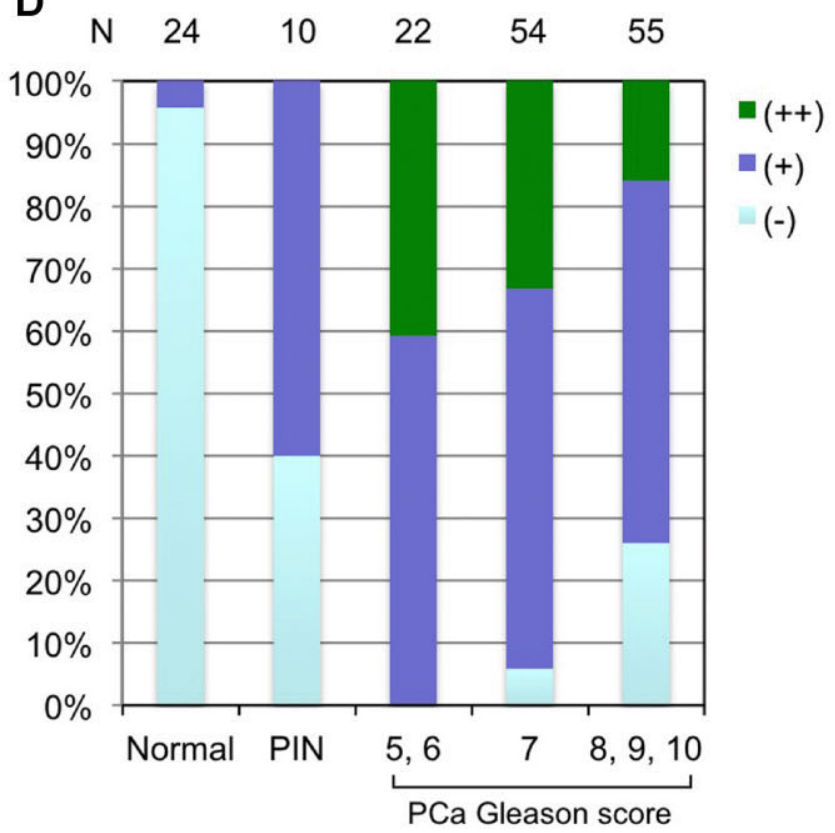

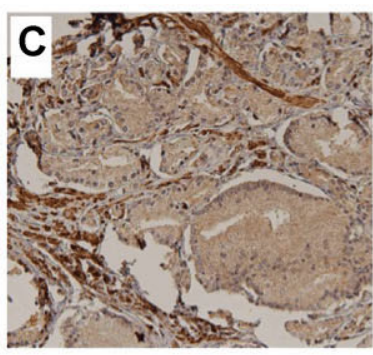

E

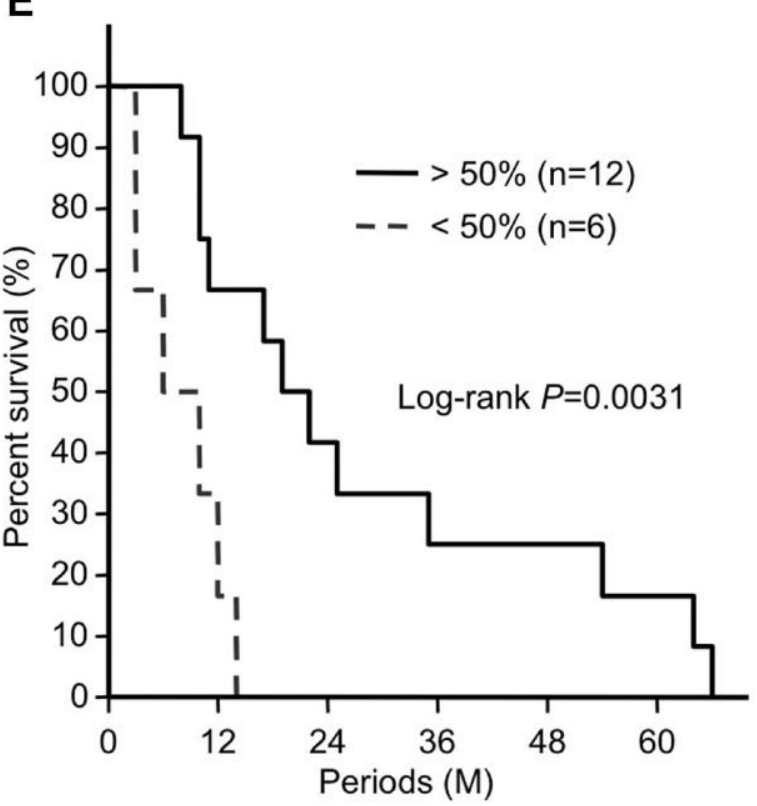

Fig. I. Immunohistochemistry of CAMKK2 in prostate tissue. Representative examples of photomicrographs (I00 $\times$ magnification) showing CAMKK2 expression in the normal prostate and prostate cancer on tissue microarray analysis. A: CAMKK2 expression in normal prostate tissue (intensity-). B: CAMKK2 expression in prostate cancer with Gleason score 8 (intensity+). C: CAMKK2 expression in prostate cancer with Gleason score 7 (intensity++). D: Immunohistochemistry of CAMKK2 on prostate tissue microarray. E: Kaplan-Meier estimates of PSA-progression free survival for the indicated CAMKK2-positive area. The patients were classified in two groups by the rate of the CAMKK2-positive area (solid line: the rate of CAMKK2-positive area is more than $50 \%$, dash line: the rate of CAMKK2-positive area is $<50 \%)$.

CAMKK2 expression positive cells occupied $<50 \%$ had a poorer PFS significantly than the patients with the area that CAMKK2 expression positive cells occupied was bigger than 50\% (median PFS 6 vs. 19 months, respectively; $P=0.0031$ ).

\section{Androgen Induces CAMKK2 Expression}

Since PCa is generally androgen-dependent before ADT, we confirmed if dihydrotestosterone (DHT) can induce CAMKK2 in LNCaP cells. DHT-induced CAMKK2 mRNA in a dose-dependent manner in $24 \mathrm{hr}$ (Fig. 2A). Western blot analysis also revealed that DHT-induced $72 \mathrm{kDa}$ CAMKK2 protein expression in a dose-dependent manner. In contrast, androgen-deprivation treatment from the medium in which $\mathrm{LNCaP}$ cells were cultured in the presence of $10 \mathrm{nM}$
DHT gradually repressed CAMKK2 mRNA and protein expression (Fig. 2B).

\section{Overexpression of CAMKK2 in LNCaP Cells Represses Cell Proliferation}

To explore the function of CAMKK2 on PCa cells, we first generated stably CAMKK2 overexpressed LNCaP cells (LNCaP/GFP-CAMKK2). Ninety-nine $\mathrm{kDa}$ GFP-fused CAMKK2 protein was dominantly expressed in cytoplasm of LNCaP/GFP-CAMKK2 cells (Fig. 2B and C). DHT of various concentrations did not change AR mRNA expression in both LNCaP/GFP and LNCaP/GFP-CAMKK2 cells. In contrast, AR protein level in LNCaP/GFP-CAMKK2 cells was lower than that in LNCaP/GFP cells irrespective of DHT (Fig. 2D). 
A

RT-PCR

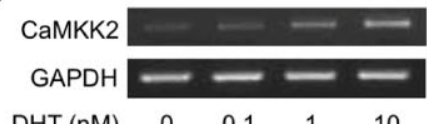

$\begin{array}{lllll}\mathrm{DHT}(\mathrm{nM}) & 0 & 0.1 & 1 & 10\end{array}$

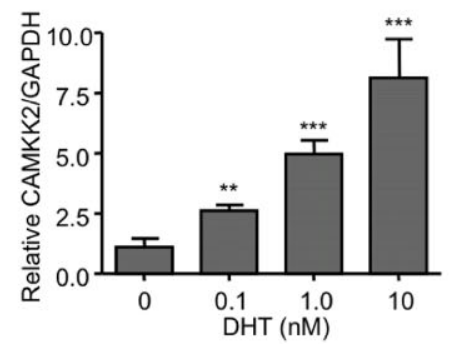

Western blot

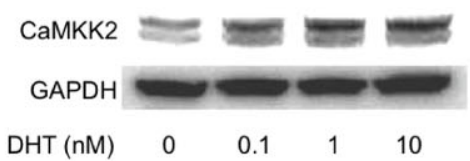

C

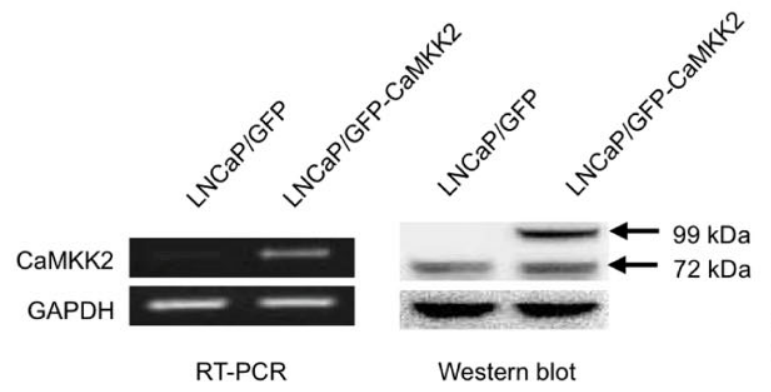

E

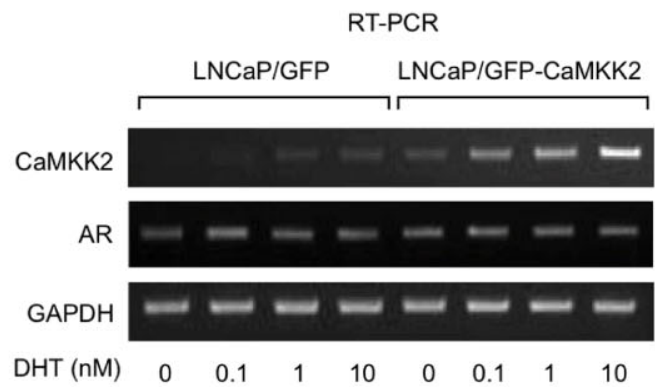

B
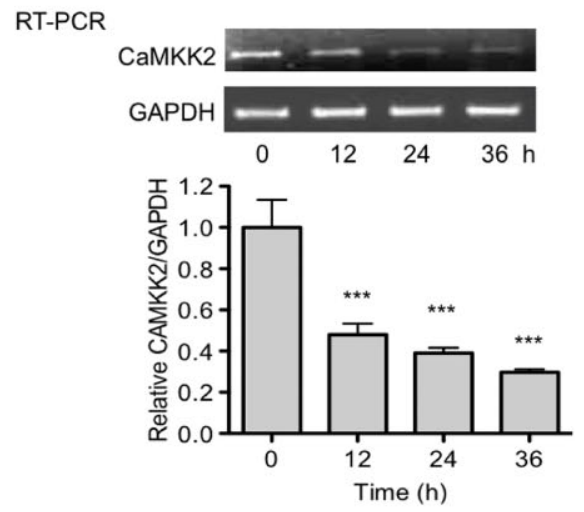

Western blot

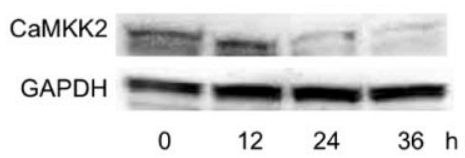

D

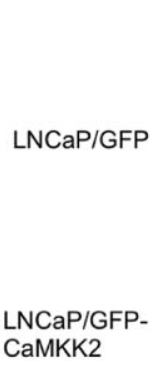

$$
\text { САMKK2 }
$$

Nucleus
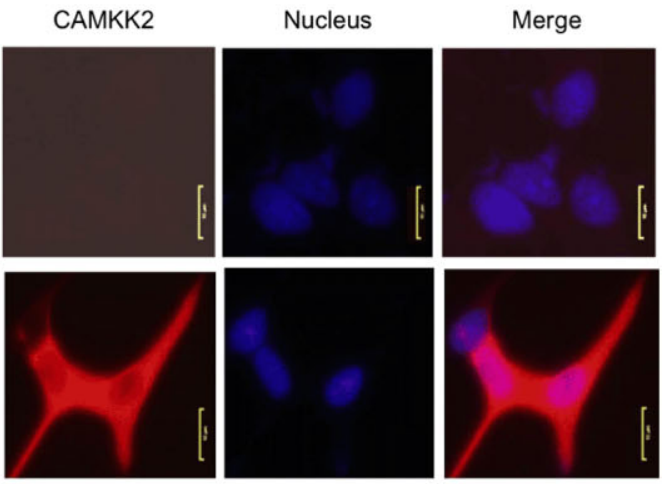

Western blot

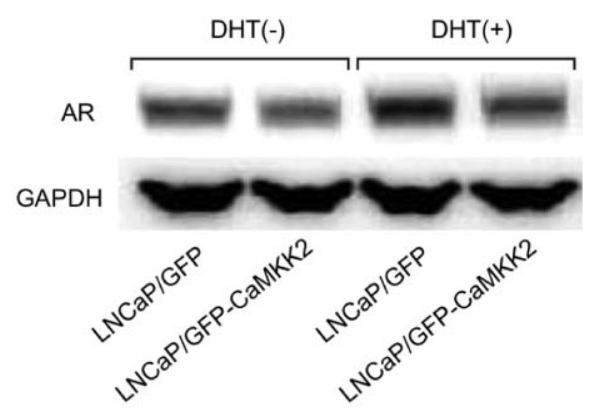

Fig. 2. Induction of CAMKK2 by androgen and generation of stable transformant of CAMKK 2 in $L N C a P$ cells. A: $L N C a P$ cells were treated with DHT $(0,0.1,1.0$, and $10 \mathrm{nM})$ for $24 \mathrm{hr}$ and total RNAs were extracted and subjected to real-time RT-PCR of CAMKK2 and GAPDH. Whole cell lysate from each sample was also subjected to Western blot analysis. Anti-CAMKK2 antibody and anti-GAPDH antibody were used for detection of $72 \mathrm{kDa}$ CAMKK2 and $37 \mathrm{kDa}$ GAPDH protein, respectively. B: Twenty-four hours after seeding of LNCaP cells, cells were treated with $10 \mathrm{nMDHT}$ for $12 \mathrm{hr}$. Then the medium was changed to DMEM-5\% CCS to remove DHTand the cells were cultured for 12, 24, and $36 \mathrm{hr}$ and harvested. The expression level of CAMKK2 mRNA and protein was subjected to real-time RT-PCR and Western blot analysis. C: Generation of stable transformant of GFP or GFP-CAMKK2 in LNCaP cells. Total RNA and whole cell lysate from LNCaP/GFP and LNCaP/GFP-CAMKK2 were subjected to RT-PCR and Western blot analysis, respectively. D: Immunofluorescence analysis of CAMKK2 in LNCaP/GFP and LNCaP/GFP-CAMKK2. Immunofluorescence analysis were performed using mouse anti-CAMKK2 antibody (red) as described in the Materials and Methods Section, and the blue signal represents nuclear DNA staining (400 $\times$ magnification). E: After cells were treated with 0, 0.1, I.0, and $10 \mathrm{nM}$ DHT for $24 \mathrm{hr}$, total RNAs were extracted and subjected to RT-PCR of AR and GAPDH.Whole cell lysates were subjected toWestern blot analysis of $110 \mathrm{kDa}$ AR and GAPDH $48 \mathrm{hr}$ after I0 nMDHT-treatment. 
We further performed luciferase reporter assay to confirm how CAMKK2 overexpression affect AR activity in LNCaP cells. LNCaP/GFP and LNCaP/ GFP-CAMKK2 cells were transfected with a luciferase reporter (pGL3PSAp-5.8) driven by $5.8 \mathrm{kbp}$ PSA promoter that includes strong $4.1 \mathrm{kbp}$ upstream androgen-response element (ARE3) and weak ARE1 and 2 [25]. The PSA promoter activity induced by DHT in $\mathrm{LNCaP} / \mathrm{GFP}-\mathrm{CAMKK} 2$ cells was two to four times lower than in LNCaP/GFP cells (Fig. 3A). Moreover,
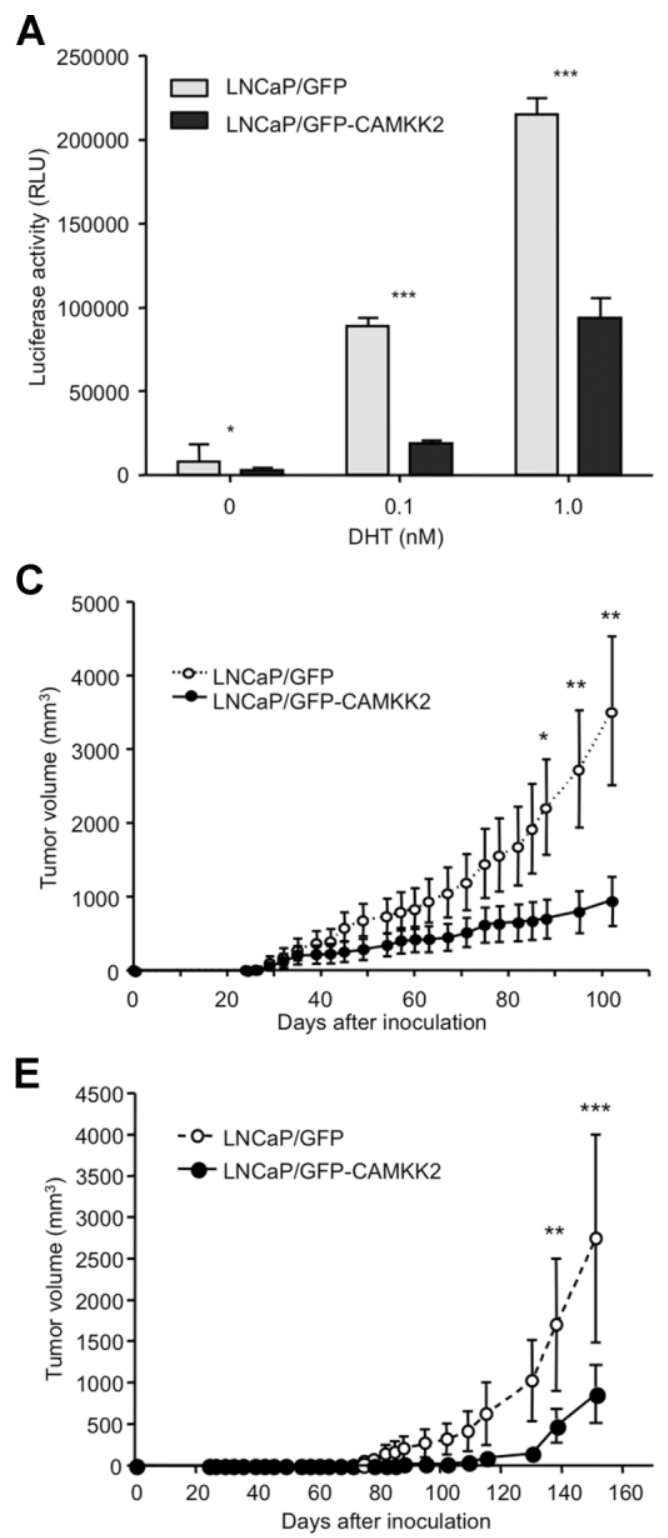

basal level of PSA promoter activity in the absence of DHT was also reduced in LNCaP/GFP-CAMKK2 cells by 2.7-fold compared with LNCaP/GFP cells.

Since CAMKK2 overexpression down-regulated PSA promoter activity in the presence and absence of DHT, we also explored the effect of CAMKK2 overexpression on $\mathrm{LNCaP}$ cell proliferation. The proliferation rate of $\mathrm{LNCaP} / \mathrm{GFP}-\mathrm{CAMKK} 2$ cells without DHT was diminished compared with LNCaP/GFP cells $(P<0.05 ;$ Fig. 3B). Moreover, whereas the

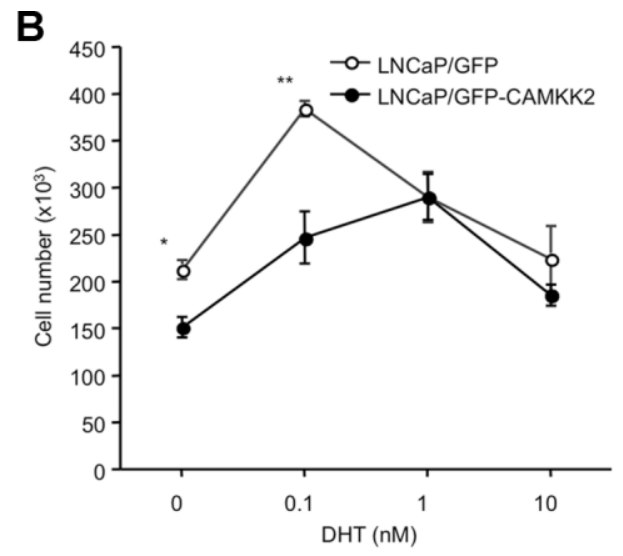

D

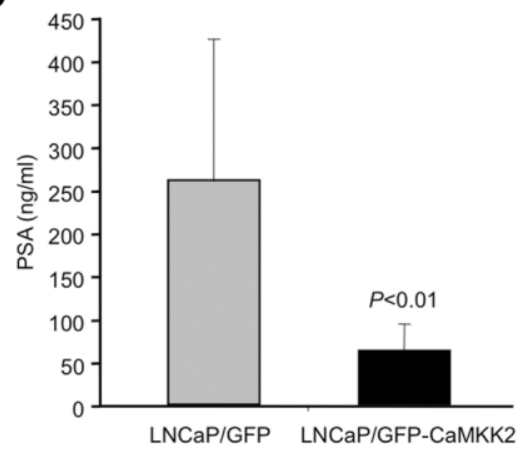

$\mathbf{F}$

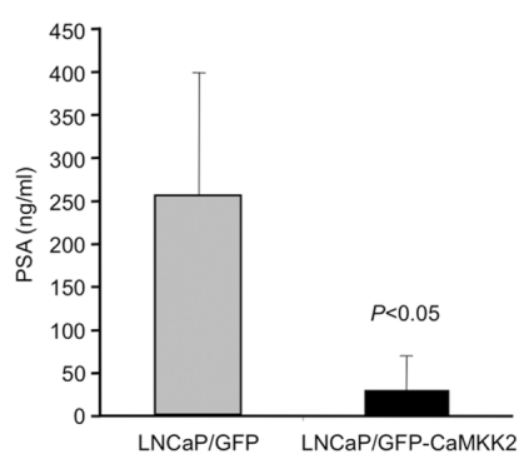

Fig. 3. Effect of CAMK2 overexpression on LNCaP cells. A: After transfection of LNCaP/GFP and LNCaP/GFP-CAMKK2 cells with PGL3PSAp-5.8, cells were treated with 0, 0.1, or $1.0 \mathrm{nMDHT}$ for $24 \mathrm{hr}$ and luciferase activity was examined. B: After LNCaP/GFP and LNCaP/ GFP-CAMKK 2 cells were treated with $0,0.1,1.0$, and $10 \mathrm{nM}$ DHT for 4 days, the numbers of LNCaP/GFP and LNCaP/GFP-CAMKK2 cells were counted. C: After $2 \times 10^{6} \mathrm{LNCaP} /$ GFP, LNCaP/GFP-CAMKK2 cells were injected into dorsal subcutis of intact SCID mice, the volume of dorsal tumor was monitored every 3 or 4 days. All values are expressed as mean \pm SE. D: Enzyme immunoassay of PSA was performed in serum of SCID mice that were sacrificed. E: After $2 \times 10^{6} \mathrm{LNCaP} / \mathrm{GFP}, \mathrm{LNCaP} / \mathrm{GFP}-\mathrm{CAMKK} 2$ cells were injected into dorsal subcutis of castrated SCID mice, the volume of dorsal tumor was monitored. F: Enzyme immunoassay of PSA was also performed as (D). 
proliferation of LNCaP/GFP cells was stimulated in $0.1 \mathrm{nM}$ DHT most, the proliferation of LNCaP/ GFP-CAMKK2 cells was stimulated in $1 \mathrm{nM}$ DHT most $(P<0.001$; Fig. $3 \mathrm{~B})$. This result suggested that the androgen-sensitivity of LNCaP cells was diminished by CAMKK 2 overexpression.

To assess the effect of CAMKK2 overexpression on tumorigenesis in xenograft model, LNCaP/GFP and LNCaP/GFP-CAMKK2 cells were injected subcutaneously in dorsal flank of intact male SCID mice. The growth rate of LNCaP/GFP-CAMKK2 cells was significantly declined to $25 \%$ of LNCaP/GFP cells at day $115(P=0.017 ;$ Fig. $3 C)$. In accordance with growth, mean serum PSA value on sacrifice in LNCaP/GFP-CAMKK2-bearing mice was decreased by 4.2 -fold compared with LNCaP/GFP-bearing mice $(P<0.01$; Fig. 3D). We simultaneously assessed the tumorigenesis of LNCaP/GFP-CAMKK2 cells in male SCID mice castrated 1 week ago. Eventually, the growth rate of $\mathrm{LNCaP} / \mathrm{GFP}$ and $\mathrm{LNCaP} / \mathrm{GFP}$ CAMKK2 cells was decrease in castrated mice compared with intact mice (compare Fig. $3 \mathrm{C}$ and E). Then the growth rate of LNCaP/GFP-CAMKK2 cells was declined to $15 \%$ of $\mathrm{LNCaP} / \mathrm{GFP}$ cells in castrated mice at day $130(P<0.05 ;$ Fig. $3 E)$. Serum PSA value on sacrifice in LNCaP/GFP-CAMKK2-bearing mice also decreased by 8.8 -fold compared with LNCaP/ GFP-bearing mice $(P<0.05$; Fig. 3F). These results suggested that CAMKK2 overexpression in $\mathrm{LNCaP}$ cells inhibit cell proliferation in vitro and in vivo irrespective of androgen.

\section{Knockdown of CAMKK2 Induces AR Activity}

Since significant overexpression of a certain protein using a strong artificial promoter, such as CMV promoter, might cause a stress on the cell and thus decrease its growth rates. We, therefore, reduced CAMKK2 expression using small interfering RNA conversely. Two different siRNA (siCAMKK2-01 and 02) were first employed for knockdown of CAMKK2. Knockdown of CAMKK2 by siCAMKK2-01 and 02 repressed CAMKK2 mRNA expression and CAMKK2 protein expression by order of CAMKK2-01 and 02 (Fig. 4A). We evaluated the effect of knockdown of CAMKK2 on PSA promoter activity in LNCaP cells by luciferase reporter assay. In accordance with knockdown of CAMKK2, PSA promoter activity was inversely correlated with CAMKK2 protein expression (Fig. 4B). Especially, knockdown of CAMKK2 by $20 \mathrm{nM}$ siCAMKK2-01 enhanced 3.6 times PSA promoter activity induced by $0.1 \mathrm{nM}$ DHT compared with control non-target siRNA (siNT). Therefore, we chose siCAMKK2-01 for further knockdown study of CAMKK2. Knockdown of CAMKK2 by siCAMKK2 enhanced PSA promoter activity induced by $0.1 \mathrm{nM}$ DHT from 1.9 to 4.1 times compared with siNT in a dose-dependent manner (Fig. 4C). We further investigated if knockdown of CAMKK2 expression affect different androgen-inducible MMTV promoter activity. MMTV promoter induced by $1.0 \mathrm{nM}$ DHT as well as PSA promoter was enhanced by knockdown of CAMKK2 (Fig. 4D). In accordance with induction of PSA promoter activity by knockdown of CAMKK2, LNCaP cell proliferation was stimulated by knockdown of CAMKK2 (Fig. 4E). Especially, proliferation stimulation by the addition of $0.1 \mathrm{nM}$ DHT was further enhanced by knockdown of CAMKK2, suggesting that androgen-sensitivity was enhanced by down-regulation of CAMKK2 expression.

In order to confirm whether a phenomenon observed with LNCaP cells applied to other cells, we used androgen-sensitive PCa VCaP cells and performed a similar experiment. DHT-induced PSA and MMTV promoter activity in $\mathrm{VCaP}$ cells was enhanced by knockdown of CAMKK2, suggesting that this phenomenon is common events observed in androgensensitive cells (Fig. 4F).

Since overexpression of CAMKK2-reduced AR protein level in the presence of DHT as described above, we explored AR expression level on knockdown of CAMKK2 by siCAMKK2. As we expected, AR expression level that was increased $24 \mathrm{hr}$ after DHT-treatment was further elevated by knockdown of CAMKK2, although it was not changed in the absence of DHT by knockdown of CAMKK2 (Fig. 5A). To further confirm if basal PSA promoter activity induced by knockdown of CAMKK2 is related with AR activity, we employed another reporter vector driven by a $633 \mathrm{bp}$ deleted PSA promoter that includes only two weak AREs (pGL3PSAp-0.63) for this experiment. As compared with pGL3PSAp-5.8 that includes strong ARE3, LNCaP cells transfected with pGL3PSAp-0.63 showed weak induction of PSA promoter activity by DHT (two times). Interestingly, not only basal PSA promoter activity but also DHTinduced PSA promoter activity of pGL3PSAp-0.63 was not enhanced by knockdown of CAMKK2 (Fig. 5B). These results suggested that enhancement of AR promoter activity by knockdown of CAMKK2 might be mediated by not only AR stability but also other transcriptional factors related with ARE3.

\section{DISCUSSION}

In the present study, we demonstrated that CAMKK2 identified by cDNA microarray technique had a function as a putative tumor suppressor and that down-regulation of CAMKK2 causes androgenhypersensitivity during ADT. 
A

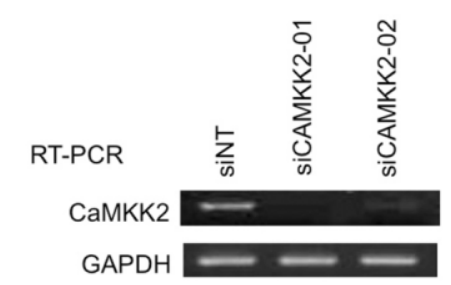

Western blot

CaMKK2

GAPDH

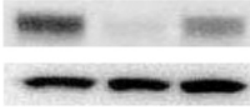

C

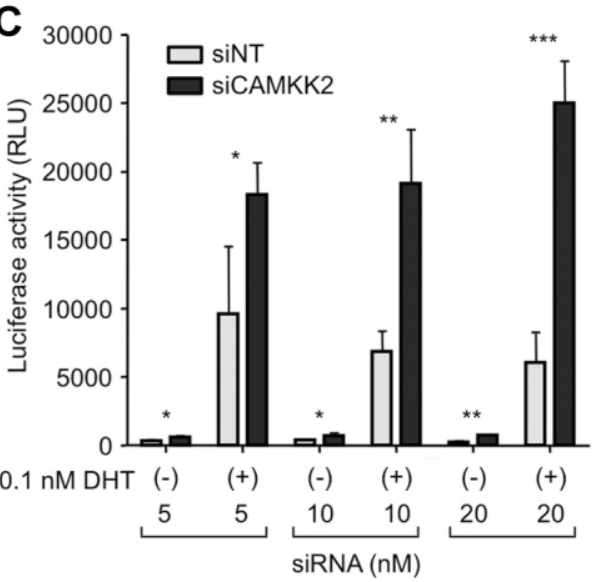

E

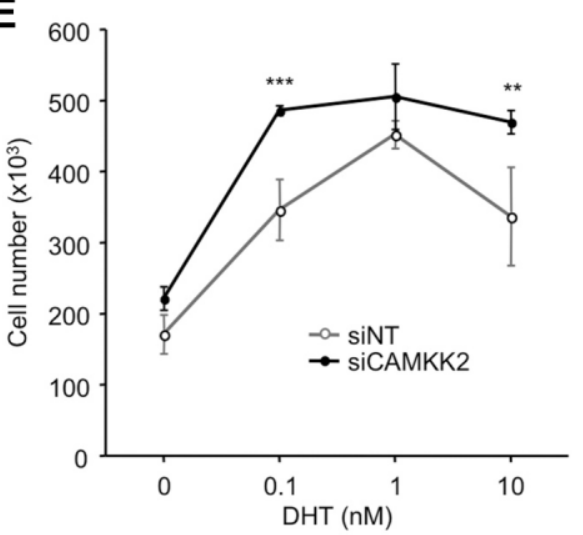

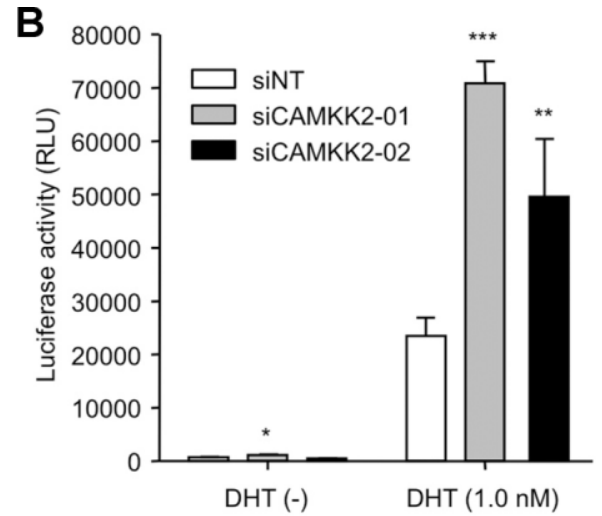

D

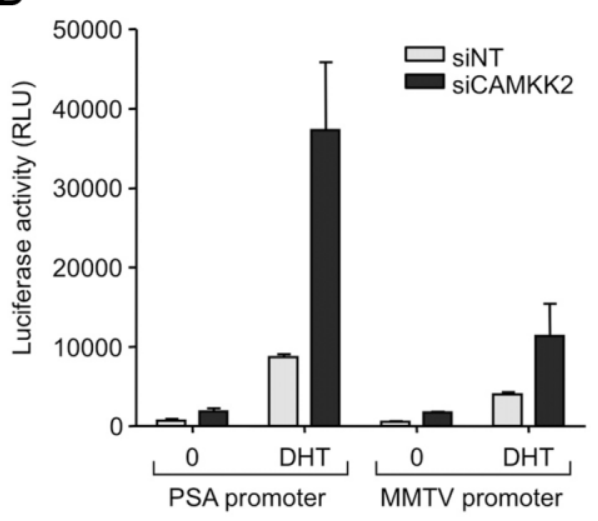

$\mathbf{F}$

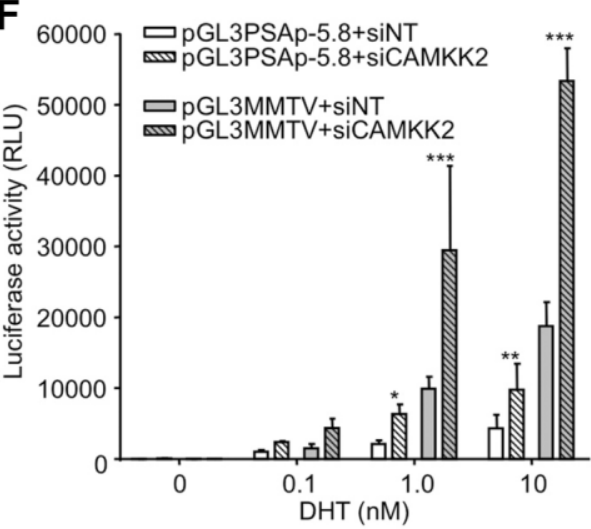

Fig. 4. Effect of knockdown of CAMKK2 expression on AR activity. A: Knockdown of CAMKK2 expression in LNCaP cells by CAMKK2 siRNA-0I and - 02 transfection. Twenty-four hours or $72 \mathrm{hr}$ after transfection with NT siRNA or CAMKK2 siRNA-0I or - 02, total RNA or total proteins from LNCaP cells were extracted and subjected to RT-PCR or Western blot analysis of CAMKK2 and GAPDH, respectively. B: Enhancement of PSA promoter activity by knockdown of CAMKK2. PSA promoter activity induced by DHTwas examined after transfection with NT siRNA or CAMKK2 siRNA-0I and -02. C: After LNCaP cells were transfected with 5, I0, or 20 nM NT siRNA or CAMKK2 siRNA for $12 \mathrm{hr}$, cells were transfected with pGL3PSAp-5.8. D: After LNCaP cells were transfected with NT siRNA or CAMKK2 siRNA, cells were transfected with pGL3PSAp-5.8 (PSA promoter) or pGL3MMTV (MMTV promoter and were treated with $0.1 \mathrm{nMDHTor} .0 \mathrm{nM}$ DHT for $24 \mathrm{hr}$, respectively. E: Effect of knockdown of CAMKK2 expression on LNCaP cell proliferation. F: Effect of knockdown of CAMKK2 on PSA promoter activity in VCaP cells. Knockdown o CAMKK2 and luciferase assay were performed as described in (D).

Eventually CAMKK2 protein was expressed more in PCa tissue samples than in normal prostate tissue in accordance with cDNA microarray analysis between normal prostate and PCa samples, suggesting that CAMMKK2 can become the useful immunohistochemical biomarker of PCa. However, the CAMKK2-negative staining in tissue microarray samples was rather increased in $\mathrm{PCa}$ patients 
A

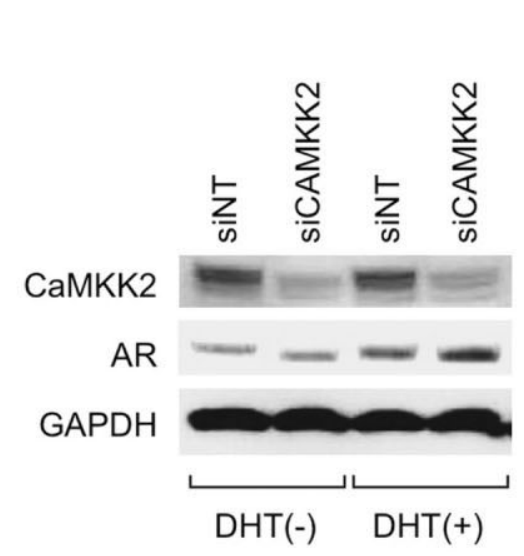

B
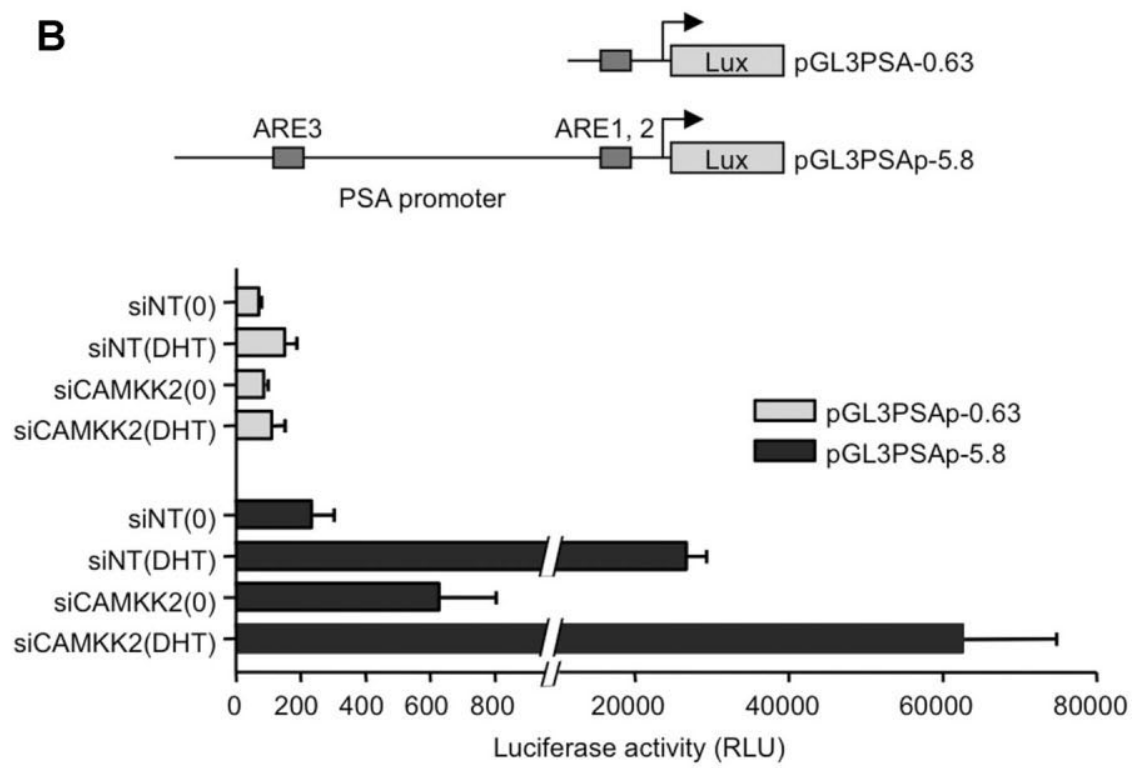

Fig. 5. Effect of knockdown of CAMKK2 on AR activity in LNCaP cells. A: After LNCaP cells were transfected with NTsiRNA or CAMKK2 siRNA, cells were treated with 0 or $10 \mathrm{nMDHT}$ for $24 \mathrm{hr}$ and whole cell lysates were extracted for Western blot analysis of AR and GAPDH. B: LNCaP cells were transfected with NT siRNA or CAMKK2 siRNA. Then LNCaP cells were transfected with pGL3PSAp-0.63 or PGL3PSAp-5.8 and treated with 0 or I nMDHT for $24 \mathrm{hr}$, and luciferase assay was performed.

with high Gleason score. Moreover, when an expression of CAMKK2-positive area was narrow in PCa tissue, PSA-progression free survival rate after first ADT was low. The phenomenon that CAMKK2 is expressed in PCa more than in normal prostate may be contribution to the carcinogenesis of PCa. However, once $\mathrm{PCa}$ is formed to some size, a function of CAMKK2 may changes and CAMKK2 may act to make a cell proliferation inhibited. In contrast, among the various cells and organs, homeostasis is often preserved by the feedback function through various hormones and cytokines. Even if it is PCa cells, expression of CAMKK2 that is promoted by androgen may regulate a rapid cell proliferation by negative feedback, so called forming a negative regulatory loop to maintain a balance in proliferation between androgen and CAMKK2. It is well-known phenomenon that the proliferation of LNCaP cells shows biphasic pattern on androgen concentration: DHT of the high concentration rather inhibited the LNCaP proliferation [26] (Figs. 3B and 4E). Nevertheless, CAMKK2 expression was induced by DHT in a dosedependent manner (Fig. 2A). Furthermore, overexpression of CAMKK2 repressed the proliferation of LNCaP cells and attenuated androgen-sensitivity, and that down-regulation of CAMKK2 stimulated cell proliferation and enhanced androgen-sensitivity for DHT of the low concentration. Thus, low expression of CAMKK2 as a tumor suppressor before ADT or down-regulation of CAMKK2 by ADT may contribute relapse of PCa in response to adrenal androgen of the low concentration at later stage. This similar phenomenon is also observed in suppressors of cytokine signaling (SOCS)-3. SOCS-3 as well as CAMKK2 are up-regulated by androgen in PCa cell lines and inhibit androgen-mediated proliferation [27].

How does CAMKK2 expression repress AR-signaling axis and proliferation? One of its mechanisms may be involvement of AR protein. Overexpression of CAMKK2 repressed AR protein level (Fig. 2). Pelley et al. described that $\mathrm{Ca}^{2+}$ stimulated AR breakdown in vitro and in vivo and that calmodulin bound to AR seemed to play a role in calpain-mediated cleavage of AR in LNCaP cells [28,29]. Together, the effect of CAMKK2 on AR protein stability in the presence of androgen may change AR-signaling axis.

The other reason for influence of CAMKK2 on cell proliferation may be the activation of AMPK by AMPK phosphorylation. CAMKK2 is upstream protein kinase for AMPK [30]. Zhou et al. demonstrated that inactivation of AMPK by dominant negative AMPK mutant accelerated cell proliferation and promoted malignant behavior such as increased cell migration and anchorage-independent proliferation mediating through lipopolysaccharide-induced tumor necrosis factor (TNF) alpha factor (LITAF) and TNF superfamily member 15 (TNFSF15) [31,32]. Serine-threonine liver kinase B1 (LKB1) known as a tumor suppressor also activates AMPK, and have crucial roles in cell proliferation [33]. One of the major 


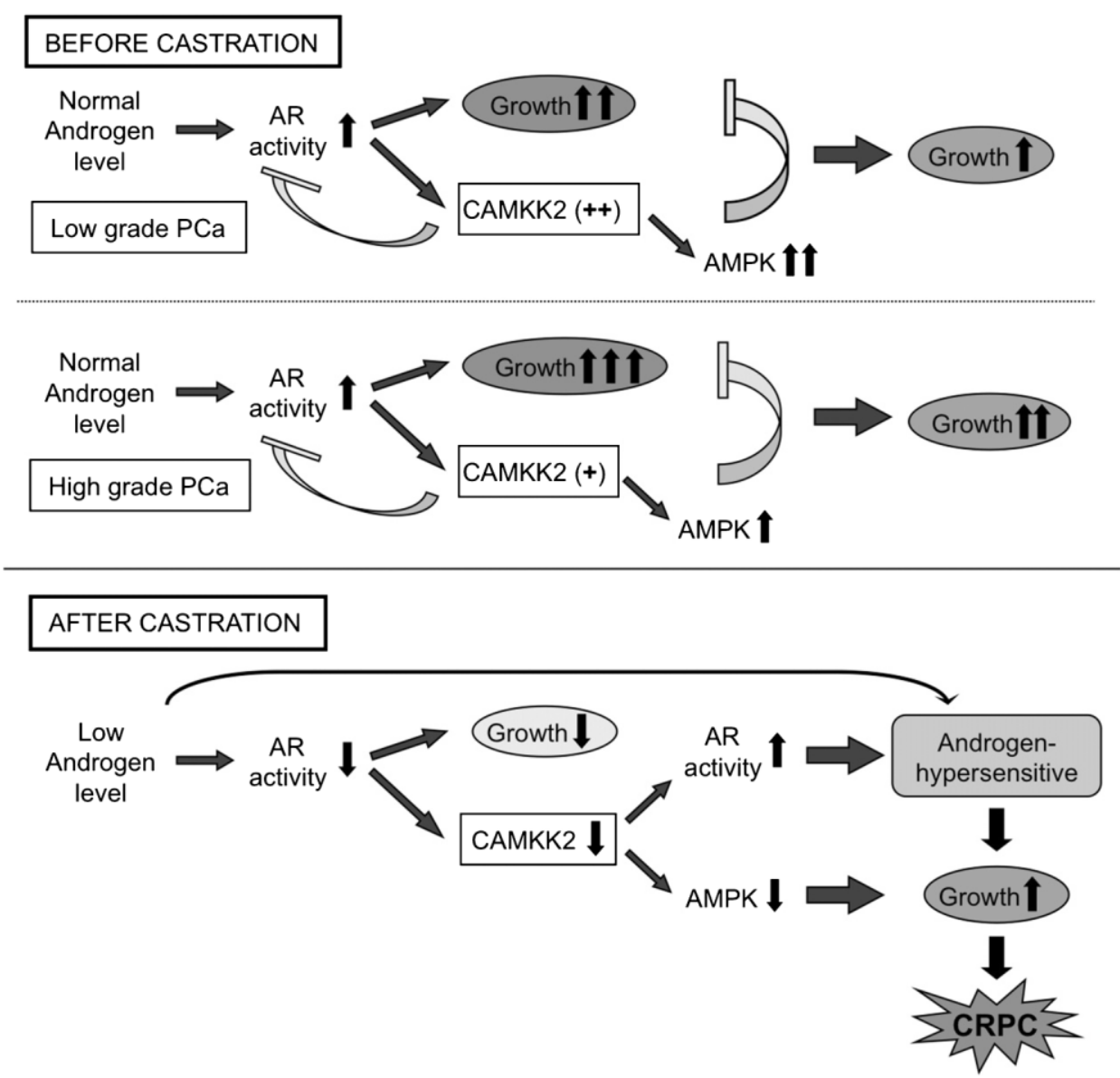

Fig. 6. Function of CAMKK2 on PCa. The role of CAMKK2 on PCa growth and a mechanism of transition to CRPC during ADT.

proliferation regulatory pathways controlled by LKB1-AMPK is the mTOR (mammalian Target of Rapamycin) pathway. The mTOR pathway is inhibited through tuberous sclerosis complex 2 (TSC2) known as a tumor suppressor [33]. Activation of AMPK by CAMKK2 overexpression might repress PCa proliferation through mTOR inhibition as well as LKB1. Park et al. [34] demonstrated that AMPK was highly activated in $40 \%$ of human PCa and act as a metabolic survival factor. In breast cancer, reduced phsphorylated AMPK signal was significantly associated with higher histological grade and axillary node metastasis [35]. These reports suggest that the regulation of CAMKK2 on cell proliferation in PCa is mediated through AMPK activation.

However, the function of CAMKK2-AMPK pathway is still controversial $[19,20]$. Frigo et al. [19] and Massie et al. [20] demonstrated that CAMKK2induced migration and invasion of $\mathrm{LNCaP}$ cells and stimulated LNCaP cell growth mediating through phosphorylation of AMPK. IHC in our study revealed that the ratio of CAMKK2-negative staining in the $\mathrm{PCa}$ with the high-grade Gleason score that has more malignant potential was increased compared with the low-grade Gleason score. Furthermore, our present study that CAMKK2-AMPK pathway inhibited PCa growth is rather coincident with Zhou et al. [31] and Hadad et al. [35]. It remains unclear why CAMKK2-AMPK pathway show different functions. The function of CAMKK2 may change at different situation, such as late stage of CRPC. Further study will be needed to clarify this pathway.

As described in Figure 6, these observations raise the intriguing mechanism that hormone-naive $\mathrm{PCa}$ that initially responds to ADT becomes castrationresistant. Before hormonal therapy, CAMKK2 is expressing in response to androgen. It may be the cause why a proliferation rate of the PCa is generally slow compared with other cancers, such as lung cancer and colon cancer that expression of CAMKK2 controls excessive growth of PCa through activation of AMPK or other signals. However, when ADT is conducted for PCa, expression of CAMKK2 in the PCa attenuates, and activation of AMPK is repressed. As a result, PCa changes in the state that is androgen-hypersensitive, and androgen of the low 
concentration promotes growth of the PCa and shifts in CRPC.

Atorvastatin known as a statin famous for the control of hypercholesterolemia also activates CaMKK2 as an upstream kinase of AMPK in endothelium [36]. Recently, Zheng et al. demonstrated that administration of a combination of atorvastatin and celecoxib might be an effective strategy for the prevention of $\mathrm{PCa} \mathrm{LNCaP}$ cell progression from androgen dependence to androgen independence in castrated SCID mice [37]. Although down-regulation of CAMKK2 assists recurrence as described above, the continuous activation of CAMKK2 with some reagents such as atorvastatin may prevent recurrence during ADT.

In conclusion, we suggest that ADT downregulates $\mathrm{CAMKK} 2$ and that CAMKK2 subsequently stabilize AR that is a key mediator of hormonal signaling. Moreover, the finding that CAMKK2 expression is reduced in more malignant PCa suggests that loss of CAMKK2 may enhance androgen signaling and promote prostate cell proliferation. Furthermore, the fact that overexpression of CAMKK2 in vivo reduces tumor growth suggests that reactivation of CAMKK2 by development of new drugs may be a new strategy to prolong the period to respond ADT and inhibit PCa progression.

\section{ACKNOWLEDGMENTS}

We thank Y. Kawabuchi for skilled technical assistance (Kanazawa University). This study was supported by Grant-in-Aid for Scientific Research on Priority Areas from the Ministry of Education, Culture, Sport, Science, and Technology of Japan (21592037).

\section{REFERENCES}

1. Siegel R, Ward E, Brawley O, Jemal A. Cancer statistics, 2011: The impact of eliminating socioeconomic and racial disparities on premature cancer deaths. CA Cancer J Clin 2011;61(4):212236.

2. Hoimes CJ, Kelly WK. Redefining hormone resistance in prostate cancer. Ther Adv Med Oncol 2010;2(2):107-123.

3. Taplin ME, Balk SP. Androgen receptor: A key molecule in the progression of prostate cancer to hormone independence. J Cell Biochem 2004;91(3):483-490.

4. Nishiyama T, Hashimoto $Y$, Takahashi K. The influence of androgen deprivation therapy on dihydrotestosterone levels in the prostatic tissue of patients with prostate cancer. Clin Cancer Res 2004;10(21):7121-7126.

5. Mizokami A, Koh E, Izumi K, Narimoto K, Takeda M, Honma S, Dai J, Keller E, Namiki M. Prostate cancer stromal cells and LNCaP cells coordinately activate the androgen receptor through synthesis of T and DHT from DHEA. Endocr Relat Cancer 2009;16:1139-1155.

6. Veldscholte J, Voorhorst-Ogink MM, Bolt-de Vries J, van Rooij HC, Trapman J, Mulder E. Unusual specificity of the androgen receptor in the human prostate tumor cell line LNCaP: High affinity for progestagenic and estrogenic steroids. Biochim Biophys Acta 1990;1052(1):187-194.

7. Duff J, McEwan IJ. Mutation of histidine 874 in the androgen receptor ligand-binding domain leads to promiscuous ligand activation and altered p160 coactivator interactions. Mol Endocrinol 2005;19(12):2943-2954.

8. Koivisto P, Kononen J, Palmberg C, Tammela T, Hyytinen E, Isola J, Trapman J, Cleutjens K, Noordzij A, Visakorpi T, Kallioniemi OP. Androgen receptor gene amplification: A possible molecular mechanism for androgen deprivation therapy failure in prostate cancer. Cancer Res 1997;57(2):314-319.

9. Steinkamp MP, O'Mahony OA, Brogley M, Rehman $\mathrm{H}_{\text {, }}$ Lapensee EW, Dhanasekaran S, Hofer MD, Kuefer R, Chinnaiyan A, Rubin MA, Pienta KJ, Robins DM. Treatmentdependent androgen receptor mutations in prostate cancer exploit multiple mechanisms to evade therapy. Cancer Res 2009;69(10):4434-4442.

10. Kang Z, Janne OA, Palvimo JJ. Coregulator recruitment and histone modifications in transcriptional regulation by the androgen receptor. Mol Endocrinol 2004;18(11):2633-2648.

11. Fujimoto N, Miyamoto H, Mizokami A, Harada S, Nomura M, Ueta Y, Sasaguri T, Matsumoto T. Prostate cancer cells increase androgen sensitivity by increase in nuclear androgen receptor and androgen receptor coactivators; a possible mechanism of hormone-resistance of prostate cancer cells. Cancer Invest 2007;25(1):32-37.

12. Debes JD, Comuzzi B, Schmidt LJ, Dehm SM, Culig Z, Tindall DJ. p300 regulates androgen receptor-independent expression of prostate-specific antigen in prostate cancer cells treated chronically with interleukin-6. Cancer Res 2005;65(13):59655973.

13. Holzbeierlein J, Lal P, LaTulippe E, Smith A, Satagopan J, Zhang L, Ryan C, Smith S, Scher H, Scardino P, Reuter V, Gerald WL. Gene expression analysis of human prostate carcinoma during hormonal therapy identifies androgenresponsive genes and mechanisms of therapy resistance. Am J Pathol 2004;164(1):217-227.

14. Cooper CS, Campbell C, Jhavar S. Mechanisms of Disease: Biomarkers and molecular targets from microarray gene expression studies in prostate cancer. Nat Clin Pract Urol 2007;4(12): 677-687.

15. Tamura $K$, Furihata $M$, Tsunoda $T$, Ashida $S$, Takata R, Obara W, Yoshioka H, Daigo Y, Nasu Y, Kumon H, Konaka H, Namiki M, Tozawa K, Kohri K, Tanji N, Yokoyama M, Shimazui T, Akaza H, Mizutani Y, Miki T, Fujioka T, Shuin T, Nakamura Y, Nakagawa H. Molecular features of hormonerefractory prostate cancer cells by genome-wide gene expression profiles. Cancer Res 2007;67(11):5117-5125.

16. Sorensen KD, Orntoft TF. Discovery of prostate cancer biomarkers by microarray gene expression profiling. Expert Rev Mol Diagn 2010;10(1):49-64.

17. Lapointe J, Li C, Higgins JP, van de Rijn M, Bair E, Montgomery K, Ferrari M, Egevad L, Rayford W, Bergerheim U, Ekman P, DeMarzo AM, Tibshirani R, Botstein D, Brown PO, Brooks JD, Pollack JR. Gene expression profiling identifies clinically relevant subtypes of prostate cancer. Proc Natl Acad Sci USA 2004;101(3):811-816.

18. Varambally S, Dhanasekaran SM, Zhou M, Barrette TR, Kumar-Sinha C, Sanda MG, Ghosh D, Pienta KJ, Sewalt RG, Otte AP, Rubin MA, Chinnaiyan AM. The polycomb group protein EZH2 is involved in progression of prostate cancer. Nature 2002;419(6907):624-629. 
19. Frigo DE, Howe MK, Wittmann BM, Brunner AM, Cushman I, Wang Q, Brown M, Means AR, McDonnell DP. CaM kinase kinase beta-mediated activation of the growth regulatory kinase AMPK is required for androgen-dependent migration of prostate cancer cells. Cancer Res 2011;71(2):528-537.

20. Massie CE, Lynch A, Ramos-Montoya A, Boren J, Stark R, Fazli L, Warren A, Scott H, Madhu B, Sharma N, Bon H, Zecchini V, Smith DM, Denicola GM, Mathews N, Osborne M, Hadfield J, Macarthur S, Adryan B, Lyons SK, Brindle KM, Griffiths J, Gleave ME, Rennie PS, Neal DE, Mills IG. The androgen receptor fuels prostate cancer by regulating central metabolism and biosynthesis. EMBO J 2011;30(13):2719-2733.

21. Mizokami A, Gotoh A, Yamada H, Keller ET, Matsumoto T. Tumor necrosis factor-alpha represses androgen sensitivity in the LNCaP prostate cancer cell line. J Urol 2000;164(3 Pt 1):800805.

22. Izumi K, Mizokami A, Li YQ, Narimoto $K$, Sugimoto $K$, Kadono Y, Kitagawa Y, Konaka H, Koh E, Keller ET, Namiki M. Tranilast inhibits hormone refractory prostate cancer cell proliferation and suppresses transforming growth factor beta1associated osteoblastic changes. Prostate 2009;69(11):12221234.

23. Mizokami A, Saiga H, Matsui T, Mita T, Sugita A. Regulation of androgen receptor by androgen and epidermal growth factor in a human prostatic cancer cell line, LNCaP. Endocrinol Jpn 1992;39(3):235-243.

24. Li Y, Mizokami A, Izumi K, Narimoto K, Shima T, Zhang J, Dai J, Keller ET, Namiki M. CTEN/tensin 4 expression induces sensitivity to paclitaxel in prostate cancer. Prostate 2010;70(1): $48-60$.

25. Schuur ER, Henderson GA, Kmetec LA, Miller JD, Lamparski HG, Henderson DR. Prostate-specific antigen expression is regulated by an upstream enhancer. J Biol Chem 1996;271(12): 7043-7051.

26. Sonnenschein C, Olea N, Pasanen ME, Soto AM. Negative controls of cell proliferation: Human prostate cancer cells and androgens. Cancer Res 1989;49(13):3474-3481.

27. Neuwirt H, Puhr M, Cavarretta IT, Mitterberger M, Hobisch A, Culig Z. Suppressor of cytokine signalling-3 is up-regulated by androgen in prostate cancer cell lines and inhibits androgenmediated proliferation and secretion. Endocr Relat Cancer 2007;14(4):1007-1019.
28. Pelley RP, Chinnakannu K, Murthy S, Strickland FM, Menon M, Dou QP, Barrack ER, Reddy GP. Calmodulin-androgen receptor (AR) interaction: Calcium-dependent, calpain-mediated breakdown of AR in LNCaP prostate cancer cells. Cancer Res 2006;66(24):11754-11762.

29. Sivanandam A, Murthy S, Chinnakannu K, Bai VU, Kim SH, Barrack ER, Menon M, Reddy GP. Calmodulin protects androgen receptor from calpain-mediated breakdown in prostate cancer cells. J Cell Physiol 2011;226(7):1889-1896.

30. Hawley SA, Pan DA, Mustard KJ, Ross L, Bain J, Edelman AM, Frenguelli BG, Hardie DG. Calmodulin-dependent protein kinase kinase-beta is an alternative upstream kinase for AMPactivated protein kinase. Cell Metab 2005;2(1):9-19.

31. Zhou J, Huang W, Tao R, Ibaragi S, Lan F, Ido Y, Wu X, Alekseyev YO, Lenburg ME, Hu GF, Luo Z. Inactivation of AMPK alters gene expression and promotes growth of prostate cancer cells. Oncogene 2009;28(18):1993-2002.

32. Zhou J, Yang Z, Tsuji T, Gong J, Xie J, Chen C, Li W, Amar S, Luo Z. LITAF and TNFSF15, two downstream targets of AMPK, exert inhibitory effects on tumor growth. Oncogene 2011;30(16):1892-1900.

33. Shackelford DB, Shaw RJ. The LKB1-AMPK pathway: Metabolism and growth control in tumour suppression. Nat Rev Cancer 2009;9(8):563-575.

34. Park HU, Suy S, Danner M, Dailey V, Zhang Y, Li H, Hyduke DR, Collins BT, Gagnon G, Kallakury B, Kumar D, Brown ML, Fornace A, Dritschilo A, Collins SP. AMP-activated protein kinase promotes human prostate cancer cell growth and survival. Mol Cancer Ther 2009;8(4):733-741.

35. Hadad SM, Baker L, Quinlan PR, Robertson KE, Bray SE, Thomson G, Kellock D, Jordan LB, Purdie CA, Hardie DG, Fleming S, Thompson AM. Histological evaluation of AMPK signalling in primary breast cancer. BMC Cancer 2009;9:307.

36. Sun W, Wang L, Shyy JY, Sun W. Abstract 1914: Atorvastatin activates CaMKK-beta as an upstream kinase of AMPK in endothelium. Circulation 2008;118:S_404.

37. Zheng X, Cui XX, Gao Z, Zhao Y, Lin Y, Shih WJ, Huang MT, Liu Y, Rabson A, Reddy B, Yang CS, Conney AH. Atorvastatin and celecoxib in combination inhibits the progression of androgen-dependent LNCaP xenograft prostate tumors to androgen independence. Cancer Prev Res (Phila) 2010;3(1): 114-124. 